\title{
A framework for probabilistic assessment of clear-water scour around bridge piers
}

\author{
Enrico Tubaldi ${ }^{1}$, Lorenzo Macorini ${ }^{1}$, Bassam Izzuddin ${ }^{1}$ Costantino Manes $^{2}$, Francesco Laio ${ }^{2}$ \\ ${ }^{1}$ Department of Civil and Environmental Engineering, Imperial College London, South \\ Kensington Campus, London, UK, email: e.tubaldi@imperial.ac.uk, \\ 1.macorini@imperial.ac.uk, b.izzuddin@imperial.ac.uk \\ 2 Department of Environmental, Land and Infrastructure Engineering, Polytechnic University \\ of Turin, Italy, email: costantino.manes@polito.it, francesco.laio@polito.it
}

\begin{abstract}
Scouring at the base of bridge piers is the major cause of bridge collapses worldwide. Computing the scour risk of bridge foundations is therefore key for a correct management and allocation of resources for maintenance and scour mitigation works. Existing riskassessment models compute the vulnerability of bridge foundations to scour by comparing the equilibrium scour depth associated with peak-flow discharges characterised by a given return period (usually of 100-200 years) with the critical foundation depth of the bridge. This approach neglects completely the history-dependent and time-dependent nature of scour. Yet, it is well known that bridge collapses can often be induced by the accumulation of scour during multiple flood events.

This study aims at developing a novel probabilistic framework for the computation of bridgepier vulnerability to scour using a Markovian approach to account for memory effects in scour development. The paper focuses on the case of local pier scour occurring in clear-water conditions whereby cumulative effects are significant, well understood and known to be the cause of recent reported bridge collapses.

A simplified numerical example consisting of an idealised bridge pier in a canal is considered to clarify the application of the proposed framework and to shed light on the effects of some assumptions introduced to simplify the probabilistic scour assessment.
\end{abstract}

Keywords: Scour, Risk assessment, Bridges, Markov process, Flood occurrence.

\section{INTRODUCTION}

Scouring of pier and abutment foundations has been widely recognized as the main cause of bridge collapse and damage, causing significant direct and indirect losses to the infrastructure system of rail and road networks [1]. In general, scour can be divided into different components: general aggradation-degradation (long term and short term), contraction, and local scour [2]. Local scour, which is the object of this paper, is caused by turbulent vortices forming at the base of bridge foundations impinged by a river current. Local scour can occur in so-called clear-water and live-bed conditions, which are characterized by the absence and presence of sediment transport in the undisturbed flow upstream of the bridge, respectively. Major floods usually tend to establish both types of scour, with live-bed conditions occurring at high flow rates and clear-water conditions occurring at low flow rates of an hydrograph 
[3]-[5]. Scour holes that develop under live-bed conditions are commonly subjected to refilling, before being eroded again during the recession limb of the hydrograph, when clearwater scour can be established.

In engineering-design practice, scour prediction is typically based on the evaluation of the equilibrium scour depth associated with a discharge of a given return period. The equilibrium scour depth is defined as the asymptotic scour depth that a pier (or an abutment) experiences after a long exposure to a steady flow. Typical design events adopted in US and in UK are those with a return period of 100 yrs or 200 yrs [1],[6]. However, it should be acknowledged that during its service life a bridge is exposed to a large range of flood-hydrographs, some of which may have peaks exceeding the discharge corresponding to the assumed design-return period. Moreover, many others will be smaller but still capable of causing scour at the bridge within the service life.

In the last decades, several methodologies have been proposed for evaluating bridge vulnerability to scour (see e.g. [7],[8]). Most of these frameworks are based on two strong assumptions: 1) the scour depth that results from exposure to a single flood event is independent from past events, 2) attainment, within a flood event, of the equilibrium scour depth for the given flood discharge, corresponding to assuming a stationary hydrograph of infinite duration [9]-[11]. However, a more rigorous assessment of vulnerability to scour should consider the fact that short duration floods or floods of minor intensity may not result in the critical scour depth of a system being exceeded, but they may cause partial erosions, making it easier to reach the maximum scour depth during the subsequent flood.

Very few studies have relaxed the assumption of independence of scour events by proposing a more accurate modelling approach that accounts for memory effects in the scour process. In this context, Van Noortwijk et al. [12] addressed stochastic modelling of scour accumulation but their work relies on the equally strong hypothesis of independent and stationary gammadistributed scour increments from one flood to another. Johnson and Ayyub [13] and later Brandimarte et al. [14] and Briaud et al. [15] developed probabilistic frameworks for the scour temporal evolution that are based on the Monte Carlo simulation of a set of hydrographs for the service life of the bridge and the evaluation of the corresponding statistics of the scour depth. In Johnson and Ayyub [13], the sample storms are generated based on the information given by partial duration series and the scour formulae utilised in the model are targeted to sand and gravel beds. In Brandimarte et al. [14] and Briaud et al. [15] a stochastic process is fitted to the historic record and used to generate replicates of hydrologic series with the same statistical properties as the observed streamflow sequence. The SRICOS-EFA method [16], developed for cohesive soils, is then used to calculate the scour depth associated with each replicate of the hydrologic record and thus to derive the scour statistical distribution.

A simpler approach to the problem at hand could be based on Markovian modelling [17], i.e., on the assumption that the susceptibility to increase (or eventually decrease) scour during one event, given the features of the flood, depends on the scour level accumulated until the occurrence of the event itself, rather than on the entire flood and scour history. This paper follows this approach and illustrates a probabilistic framework for scour risk assessment which is capable of describing the scour progression over time by accounting for the occurrence of subsequent flood events. In particular, the scour progression is evaluated by combining the results of flood hazard analysis, providing the description of the uncertainty in the flood occurrence, intensity, and on the hydrograph shape, with that of hydraulic analysis, providing the information on the scour temporal evolution for an event of a given intensity. The proposed approach also allows accounting for the uncertainties in the scour prediction 
formula and in the measurement of the initial scour hole, which is useful when the scour risk of existing bridges needs to be evaluated.

In general, the aim of the study is to present a novel probabilistic approach that allows for the probabilistic assessment of scour by taking into account key temporal effects associated with scour evolution in time during a single flood event and scour accumulation as a consequence of multiple floods. The analysis is restricted to the case of local scour in clear-water conditions and this is justified by three reasons: firstly, multiple floods inducing clear-water conditions do lead to cumulative erosion as refilling processes do not take place as in live-bed conditions [3],[18]. Secondly, during an individual flood event clear-water scouring evolves much more slowly than in live-bed conditions, whereby the attainment of the equilibrium scour depth associated with the peak flow is not such a stringent hypothesis [2],[3],[5],[18]. Thirdly and most importantly, contrary to common belief, the scour accumulation associated with multiple floods having a very low return period, and hence presumably inducing clearwater scouring, have been documented as an important cause of multiple bridge failures [19], meaning that the problem investigated herein is very relevant from a practical point of view. Recent works in the literature have also stressed the fact that the problem of scour accumulation under multiple clear-water flood events has not received sufficient attention to date (see e.g. [20]). The rest of the paper is structured as follows. Next section illustrates the general framework for probabilistic scour assessment. Subsequently, the hydrologic, hydraulic and scour analysis steps are described in detail. Finally, a simplified numerical examples is considered to show the application of the proposed scour assessment procedure and evaluate the importance of some factors such as the initial scour state, temporal effects, and memory effects.

\section{PROBABILISTIC FRAMEWORK FOR PROBABILISTIC SCOUR ASSESSMENT}

The evaluation of the failure probability of bridges exposed to scouring can be cast in the form of a time-variant reliability problem, where one aims at estimating the first-passage probability of exceeding one or more limit states related to the bridge performance during the design life time. The performance function for a single limit state can be written as [21]:

$$
G(t)=R-S(t)
$$

where $t$ denotes the time, whose initial value is assumed equal to zero, $S(t)$ is the timevariant random variable describing the scour depth at time $t$, and $R$ is the bridge capacity, i.e., the critical level of scour that corresponds to the attainment of the limit state. If the collapse limit state is of interest, in the case of a bridge with shallow foundations $R$ can be assumed to coincide with the foundation depth. More in general a structural analysis is required to obtain an accurate estimate of the effects of scour and of the critical scour levels that induce failure in bridges. This analysis is out of the scope of the present study, which focuses on the evaluation of $S(t)$, as discussed in the next section.

Under the assumption of deterministic capacity, the instantaneous probability of failure of the bridge at time $t$, can be expressed as [22]:

$$
p_{f}(t)=P(G(t) \leq 0)=P(R \leq S(t))=1-P(S(t) \leq R)=1-p_{s}(t)
$$

where $p_{s}(t)$ denotes the survival probability at time $t$. 
Flood events can be assumed to occur randomly in time. In particular, the time $t$ can be discretized in intervals of fixed width equal to one year, and the probability of having $N=n$ flood events in the time interval $(0, t]$, i.e., $P[N(t)=n]$, can be described by an occurrence model. Accordingly, the probability of failure over the time interval can be expressed through application of the Total probability theorem as:

$$
P_{f}(t)=1-\sum_{n=0}^{\infty} P\left[\max _{k=1,2, ., n} S_{k} \leq R\right] \cdot P[N(t)=n]
$$

where $S_{k}$ denotes the scour depth at the time after the occurrence of the $k$ flood event.

The evaluation of the probability of failure due to scour thus reduces to the computation of $P\left[\max _{k=1,2, ., n} S_{k} \leq R\right]$. The relevant probability distributions can be obtained by combining the information provided by hydrologic analysis, hydraulic analysis of the flow in the channel, and scour analysis. Fig. 1 shows the conceptual flow chart of the probabilistic scour assessment through its intermediate steps. Hydrologic analysis provides the input to the hydraulic model, which in turn provides the input to the computation of scour. It is noteworthy that in some situations it may be important to account for the changes induced by scouring on the channel reach and bridge properties. For example, the development of a significant scour hole may induce also significant changes of the hydraulic parameters and flow profile for a given flow discharge. Such effects are neglected in the study, which focuses the analysis on local scour and hence assumes that the initial channel and bridge properties do not change significantly. A detailed description of each step of the framework is given in the next sections.

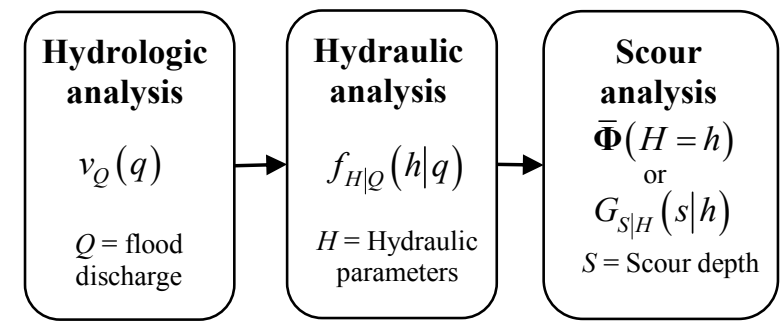

Fig. 1. Flow chart illustrating the probabilistic framework for probabilistic scour assessment.

\section{HYDROLOGIC ANALYSIS}

This analysis aims to determine the distribution of the number of floods occurring in a specific interval of time and of their magnitudes. For probabilistic scour assessment purposes it is not necessary to consider the whole discharge time series, but it is sufficient to retain only those peaks whose magnitude exceeds a minimum threshold for scour activation, $q_{0}$. Only flows with magnitude $Q$ greater than $q_{0}$ are considered to be potentially hazardous. Any streamflow hydrograph can be interpreted as a sequence of nearly instantaneous hydrograph peaks separated by relatively long periods of low flow. Because of the nature of the phenomenon, the number of these peaks in a certain interval of time $[0, t]$ and their magnitudes are random variables. Since the number of peaks in $[0, t]$ is random, the times when these peaks emerge are random variables too [23]-[26]. 


\section{Rate of occurrence of flood events}

The flood arrivals (i.e., the events with $Q>q_{0}$ ) are modelled via a homogeneous Poisson process (HPP), i.e., a process with independent and stationary increments [27]. According to this model, denoting with $\lambda$ the rate of flood events of magnitude $Q>q_{0}$, the probability that the number $N$ of event occurrences during time $t$ equals $n$ is:

$$
p_{n}(t)=P[N(t)=n]=\frac{(\lambda t)^{n}}{n !} e^{-\lambda t}
$$

with expected value and variance respectively equal to $E[N]=\lambda t$ and $\operatorname{Var}[N]=\lambda t$.

For a Poisson process, the interarrival (waiting) times have an exponential distribution:

$$
f_{T}(t)=\lambda e^{-\lambda t}
$$

with expected value equal to $\mathrm{E}[T]=1 / \lambda$.

\section{Probabilistic distribution of flood event magnitudes}

Let $Q$ be a random variable denoting the magnitude of the generic hazard event exceeding a threshold $q_{0}$. It can be shown that the number $N$ of events exceeding a threshold level $q$ is also Poisson-distributed if the following conditions are respected [27]:

1. the occurrence of each event with a given magnitude does not depend on the magnitudes of previous events;

2. the magnitudes of the flood events are independent and equally distributed with cumulative distribution function (CDF):

$$
P[Q \leq q]=F_{Q}(q)
$$

Under these assumptions, the probability of the number of events $N$ with magnitude $(Q \geq q)$ follows the law:

$$
P[N=n \mid Q>q \text { in }[0, t]]=\frac{\left(\lambda_{Q}(q) t\right)^{n}}{n !} e^{-\lambda_{Q}(q) t}
$$

where:

$$
\lambda_{Q}(q)=\lambda \cdot\left(1-F_{Q}(q)\right)=\lambda G_{Q}(q)
$$

where $G_{Q}(q)$ denotes the complementary cumulative distribution function (CCDF) of $Q$.

The expected recurrence interval or return period is then:

$$
E[T]=\frac{1}{\lambda G_{Q}(q)}
$$

It is noteworthy that the CDF of the maximum annual flow $Q_{a}$ can be obtained by combining the information from the occurrence model for the hazardous events and from the CDF of magnitude exceedances; it assumes the form:

$$
P\left[Q_{a} \leq q\right]=\exp \left(-\lambda\left(1-F_{Q}(q)\right)\right)
$$

For example, assuming a Poisson distribution for the hazardous events and an exponential 
distribution for the exceedance magnitudes,

$$
F_{Q}(q)=1-\exp \left(-\left(q-q_{0}\right) / \beta\right)
$$

where $\beta$ is a scale parameter, it can be shown that the annual maxima $Q_{a}$ follow the Gumbel (EV1) distribution [23]:

$$
P\left[Q_{a} \leq q\right]=\exp \left(-\lambda \exp \left(-\left(q-q_{0}\right) / \beta\right)\right)
$$

\section{FLOOD HYDRAULIC ANALYSIS}

The aim of this analysis is to provide a probabilistic model for the hydraulic parameters of a flow which are required as an input for computing the scour evolution. For example, one may be interested in evaluating the CDF of the depth and velocity of the flow at the bridge location. Usually, if the discharge is known, the hydraulic quantities (e.g., flow depth, flow velocity, Froude number) can be derived by assuming a reasonable friction coefficient and knowing the geometry of the channel, and are all dependent on each other.

Given a flood with a certain magnitude $Q=q$, the generic hydraulic parameter is distributed with $\operatorname{CCDF} G_{H \mid Q}(h \mid q)=P[H>h \mid Q=q]$ and the occurrence of hydraulic events with magnitude $H>h$ follows a Poisson distribution, with mean annual frequency (MAF):

$$
\lambda_{H}(h)=\int_{q} G_{H \mid Q}(h \mid q) \cdot\left|d \lambda_{Q}(q)\right|
$$

where $\left|d \lambda_{Q}(q)\right|$ denotes the MAF of events of magnitude between $q$ and $q+d q$.

Given the river reach hydraulic properties and the bridge geometrical properties, the relation between the discharge and hydraulic parameters can be evaluated by employing a hydraulic model (e.g., HEC-RAS [28]) and by performing the simulations for different levels of $Q$ in the range of interest. The effects of the uncertainty in the parameters of the hydraulic model (e.g., the channel Manning coefficient) [29] can also be incorporated in the analyses via Monte Carlo simulation, i.e., by generating a set of samples of the hydraulic parameters from the assumed probabilistic distribution, and performing hydraulic analysis for each of these samples.

\section{SCOUR ANALYSIS}

The aim of this analysis is to provide a probabilistic description of the local scour depth observable for a given flood event. The output of this analysis is a probabilistic model, which expresses the probability distribution of the scour depth conditional on the hydraulic parameters only. Let $G_{S}(s)$ denote the CCDF of the scour depth for a flood event, then the conditional probability $G_{S \mid H, Q}(s \mid h, Q)=G_{S \mid H}(s \mid h)$ meaning that $G_{S}(s)$ is not directly dependent on $Q$ since the scour is assumed to be controlled only by the hydraulic parameters, which in turn depend on $Q$.

Before proceeding further, it is now worth recalling some concepts of bridge scour phenomenology, which help explaining the rationale and the relevance of the proposed probabilistic approach. As already briefly anticipated in the introductory section of this paper, 
scour can occur under so called clear-water or live-bed conditions [30],[31]. In clear-water conditions, sediment moves only in proximity of bridge foundations whereas in live-bed conditions sediment transport occurs also in the undisturbed channel upstream of the bridge, meaning that the scour hole is continuously supplied with a sediment flow rate. In the clearwater scenario, the equilibrium scour depth is approached when the flow is no longer capable of removing sediment from the hole. In the live-bed scenario, an equilibrium is attained when, over a period of time, the average amount of sediment transported into the scour hole by the approach flow is equal to the average amount of sediment removed from the scour hole due to erosive power of localised vortices. Flood events that can induce live-bed conditions are often followed by refilling processes due to the imbalance between sediment supply and removal caused by the upstream flow and localized vortices, respectively. This in turn means that multiple clear-water events are surely associated with cumulative scour depths and strong memory effects whereas multiple live-bed events are more independent as refilling processes act as discontinuities that prevent scour to grow monotonically.

In order to illustrate these concepts, Fig. 3 shows a hypothetical flood hydrograph and the corresponding evolution of the scour depth at the foundation of a bridge pier. The flow in the channel is such that live-bed conditions are attained only during the time interval $\left[t_{3}, t_{4}\right]$, while clear-water conditions are observed during many time intervals. For example, during $\left[t_{0}, t_{1}\right]$, the scour depth increases under clear-water conditions, at a rate which is higher during the ascending part of the flood hydrograph and lower during the receding limb. In the time interval $\left[t_{1}, t_{2}\right]$, the scour depth does not increase because the discharge is below the level $q_{0}$ necessary to induce scour, in $\left[t_{2}, t_{3}\right]$ it increases again under clear-water conditions. Finally, in $\left[t_{3}, t_{4}\right]$ the scour evolves under live-bed conditions, and the scour hole is partially refilled with sediment from upstream the bridge.

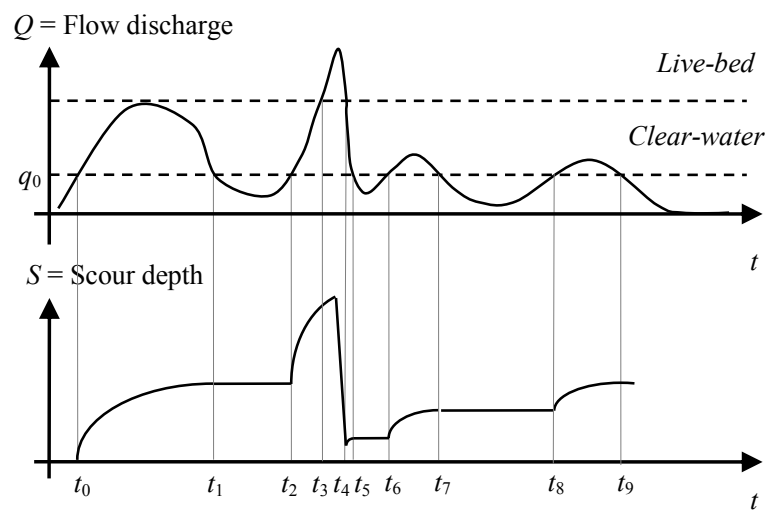

Fig. 2. Flow chart illustrating a sample evolution of the flow discharge and of the corresponding scour depth.

While the process described above is only qualitative, it suggests a different analytical treatment of the problem for clear-water and live-bed scour. For floods of high intensity, presumably inducing live-bed scouring conditions, it is plausible to assume that the equilibrium scour depth is attained almost instantaneously [30], followed by a recession stage with refilling. Thus, the probability of exceeding the critical scour depth depends only on the flow discharge (and the relevant values of the hydraulic parameters) of that particular flood event rather than on the history of scour evolution. For floods of lower intensity and hence presumably inducing clear-water scouring conditions, a single flood event is unlikely to induce a critical scour depth, but it certainly contributes to further deepen the scour hole. Therefore the repeated occurrence of multiple floods may result in the attainment of the critical scour depth, with an associated probability which increases by increasing the number 
of floods, their intensity and duration [32]. Thus, in this case it is very important to account for memory effects.

The framework outlined in this paper is therefore targeted for the analysis of clear-water scouring as this is prone to accumulate over multiple flood events and hence to show significant memory effects. Furthermore, as already discussed in the introductory part of the paper, cumulative effects induced by multiple floods triggering clear-water scouring have been identified as the cause of many bridge failures [19], which makes the proposed framework as a necessary tool for scour vulnerability analysis 1 .

The next sub-section illustrates a rigorous approach for probabilistic assessment of clearwater scour describing the scour evolution as a Markovian process accounting for memory. In Appendix A, it is shown that assuming that the scour depth at a given flood event does not depend on the previous flood events, and thus disregarding the dependency of scour evolution on previously accumulated scour depths (memoryless property), a well-known and widelyemployed formula for estimating the scour probabilistic distribution [8] is retrieved.

It is noteworthy that the application of the proposed approach requires a model for evaluating the temporal evolution of clear-water local scour at bridge piers for a given hydrograph. While a large number of empirical formulae (see [33] for a state-of-the-art review) provide only the equilibrium scour depth under a flat stationary hydrograph of infinite duration, few formulae can also quantify the evolution of the maximum scour depth with time and account for the actual hydrograph shape [9]-[11],[34]-[37]. Furthermore, in evaluating the scour depth, account should be made of epistemic uncertainties such as those relevant to the models employed for scour prediction [1],[38]. The effect of these uncertainties could be very high and could potentially overshadow that of other uncertainties such as those affecting hydraulic variables [7].

\section{Scour accumulation as a Markov process}

In this section, the scour accumulation process is modelled as a discrete-time and discretestate Markovian process [17]. For this purpose, the domain of the scour depth is partitioned into a finite number $N_{s}$ of discrete states. The first state corresponds to the scour depth that could be developed by starting from a zero initial scour depth under the least intense flood, whereas the last state corresponds to the equilibrium scour depth for the most intense flood (according to the hazard model). Let $k=1,2, . . n$ denote the number of flood events of intensity $Q$ higher than $q_{0}$ such that events of intensity $Q<q_{0}$ are not able to induce any scour. Let $p_{j}^{k}=P\left[S_{k}=s_{j}\right]$ denote the probability of being in scour state $j$ (corresponding to the depth $s_{j}$ ) for $j=1,2, . . N_{s}$, given the occurrence of the $k$-th flood event. This can be expressed as:

$$
p_{j}^{k}=\sum_{i=1}^{N_{s}} \phi_{i j}^{k} p_{i}^{k-1}
$$

where $p_{i}^{k-1}$ denotes the probability of being in scour depth state $i\left(i=1,2, . . N_{s}\right)$ at the start of the flood (the state of the system remains unchanged in the time between the end of a flood

\footnotetext{
${ }^{1}$ As an aside note, we point out that the extension of the proposed approach (i.e. inclusion of memory effects) to live-bed scour is not straightforward. This is due to the fact that the current knowledge on scour vs time in live-bed conditions is still poor and, to the best of the authors' knowledge very little is known on the dynamics of refilling processes and the temporal evolution of scour under unsteady flow conditions [39]. The common procedure that is used to carry out bridge scour vulnerability under live-bed conditions is to neglect memory effects and to assume the maximum scour depth of a flood event as the equilibrium depth associated with the peak discharge of the hydrograph. While these assumptions are commonly employed in many models, their validity have never been properly investigated.
} 
event and the next one), and $\phi_{i j}^{k}$ denotes the transition probability, i.e. the probability of reaching the scour depth state $j$, given that the initial state is $i$ :

$$
\phi_{i j}^{k}=P\left[S^{k}=s_{j} \mid S^{k-1}=s_{i}\right]
$$

This can be expressed in matrix form as:

$$
\mathbf{p}(k)=\mathbf{p}(k-1) \boldsymbol{\Phi}(k)
$$

where $\mathbf{p}(k)$ and $\mathbf{p}(k-1)$ are the scour depth probability vectors of dimension $\left(1 \mathrm{x} N_{s}\right)$ at the start and at the end of the event $k$ and $\boldsymbol{\Phi}(k)$ is the state transition matrix or transition probability matrix (TPM) of dimensions $\left(N_{s} \mathrm{x} N_{s}\right)$. It is noteworthy that while scour is a process continuous in space, it is treated here as a discrete process for simplicity and because there are no analytical expressions available for TPM $\mathbf{\Phi}(k)$, which is estimated via simulation.

The TPM at the $k$-th flood occurrence can be evaluated by combining the information on the flood hazard, the channel hydraulics, and the transition probability conditional to the channel hydraulics. In fact, it is assumed that the transition between one scour depth to another during the $k$-th flood is controlled entirely by the values of the hydraulic parameters (e.g., flow depth, flow velocity, Froude number) characteristic of that flood. In other words, conditional on the governing hydraulic parameter $H$, the TPM is constant and does not depend on $k$ (stationarity assumption):

$$
\mathbf{p}\left(k \mid H_{k}=h\right)=\mathbf{p}(k-1) \overline{\mathbf{\Phi}}\left(H_{k}=h\right)=\mathbf{p}(k-1) \overline{\mathbf{\Phi}}(H=h)
$$

where:

$$
\overline{\mathbf{\Phi}}_{i j}(H=h)=P(j-t h \text { state } \mid i-t h \text { state } \cap H=h)
$$

denote the TPM conditional on the hydraulic parameters.

By using the Total Probability Theorem, Eqn.(16) can be rewritten as:

$$
\mathbf{p}(k)=\mathbf{p}(k-1) \int_{h} \overline{\mathbf{\Phi}}(H=h)\left|d G_{H}(h)\right|=\mathbf{p}(k-1) \boldsymbol{\Phi}
$$

where:

$$
\boldsymbol{\Phi}=\int_{h} \overline{\boldsymbol{\Phi}}(H=h)\left|d G_{H}(h)\right|
$$

Since the probability distribution of the hydraulic parameters depends only on the flood discharge $Q$, by applying again the Total Probability Theorem it is possible to write:

$$
G_{H}(h)=\int_{q} G_{H \mid Q}(h \mid q)\left|d G_{Q}(q)\right|
$$

which leads to Eqn. (20) being rewritten as:

$$
\boldsymbol{\Phi}=\int_{h} \int_{q} \overline{\mathbf{\Phi}}(H=h)\left|d G_{H \mid Q}(h \mid q)\right|\left|d G_{Q}(q)\right|
$$

If there is a one-to-one relationship between the scour depth and the flow discharge, then Eqn. (22) can be expressed as: 


$$
\boldsymbol{\Phi}=\int_{q} \hat{\mathbf{\Phi}}(Q=q)\left|d G_{Q}(q)\right|=E_{Q}(\hat{\mathbf{\Phi}})
$$

where:

$$
\hat{\mathbf{\Phi}}_{i j}(Q=q)=P[j-t h \text { state } \mid i-t h \text { state } \cap Q=q]
$$

In these conditions, the stochastic scour accumulation process results to be an homogeneous Markov chain, which is completely characterized by the transition matrix $\boldsymbol{\Phi}$, and the probability mass function at the $n$-th flood occurrence can be expressed as:

$$
\mathbf{p}(n)=\mathbf{p}(0) \boldsymbol{\Phi}^{n}
$$

The conditional probability of being in depth of scour $s_{j}$ at time $t$ given $N=n$ floods starting from the initial state described by $\mathbf{p}(0)$ is:

$$
p_{j}^{n}=\sum_{i=1}^{N_{S}} \phi_{i j}^{n} p_{i}^{0}
$$

The corresponding unconditional probability of being in depth state $j$ at time $t$ is obtained as follows:

$$
p_{j}(t)=\sum_{n=0}^{\infty} p_{j}^{n} \cdot p_{n}(t)=\sum_{n=0}^{\infty} \sum_{i=1}^{N_{S}} \phi_{i j}^{n} p_{i}^{0} \cdot \frac{(\lambda t)^{n}}{n !} e^{-\lambda t}
$$

where $p_{n}(t)$ is given by Eqn.(4).

The expected value of the scour depth at time $t$ can be expressed as:

$$
E[S(t)]=\sum_{j=1}^{N_{S}} S_{j} \cdot p_{j}=\sum_{j=1}^{N_{S}} \sum_{i=1}^{N_{S}} \sum_{n=0}^{\infty} S_{j} \cdot \phi_{i j}^{n} p_{i}^{0} \cdot \frac{(\alpha t)^{n}}{n !} e^{-\alpha t}
$$

Similarly, higher order moments of $S(t)$ can be evaluated.

Based on the knowledge of $\mathbf{p}(0)$ and $\boldsymbol{\Phi}^{n}$ it is also possible to evaluate the probability of not exceedance $P\left[S_{\max , n} \leq S_{j}\right]$ for the process $S_{\max , n}(t)=\max _{k=1,2, \ldots, \mathrm{n}} S_{n}(t)$ which represents the maximum scour depth observed during the $n$ flood events. In particular, the probability $P\left[S_{\text {max }, n} \leq s_{j}\right]$ given $S_{0}=s_{i}$ can be expressed as:

$$
\psi_{i j}^{n}=P\left[S_{\text {max }, n} \leq s_{j} \mid S_{0}=s_{i}\right]=P\left[S_{1} \leq s_{j} \cap S_{2} \leq s_{j} \ldots \cap S_{n} \leq s_{j} \mid S_{0}=s_{i}\right]=\sum_{l=1}^{j} q_{i l}^{n}
$$

where $q_{i l}^{n}$ is the element at row $i$ and column $l$ of the $n$-th product of matrix $\mathbf{Q}=\left(\phi_{i l} ; i, l \leq j\right)$. This matrix is defined by deliting from matrix $\boldsymbol{\Phi}$ the rows and coulmns whose index is higher than $l$. The matrix $\Psi^{n}=\left(\psi_{i l}^{n}\right)$ can be formed, and the probability of exceeding the state $j$ can be finally expressed as:

$$
P\left[S_{\max }>s_{j} \text { in }[0, t]\right]=1-\sum_{n=0}^{\infty} \sum_{i=1}^{j} \psi_{i j}^{n} p_{i}^{0} \cdot p_{n}(t)=1-e^{-\lambda T} \sum_{n=0}^{\infty} \sum_{i=1}^{j} \psi_{i j}^{n} p_{i}^{0} \cdot \frac{(\lambda t)^{n}}{n !}
$$

Appendix A shows how this equation simplifies if the effect of memory is disregarded. 


\section{SIMPLIFIED NUMERICAL EXAMPLE}

In order to enhance the clarity of the proposed probabilistic framework, a numerical example consisting in a two-span bridge crossing a river is considered, and the evolution of the probabilistic distribution of the scour depth under clear-water conditions at the pier's submerged foundation is evaluated by considering the two approaches illustrated previously. The river channel has a rectangular cross-section of width of $B=50 \mathrm{~m}$ and bed slope $S_{0}=$ 0.0006 . The river bed is composed of very coarse sand with relative density $\gamma=1.65$ and uniform diameter $D_{50}=2 \mathrm{~mm}$, corresponding to a Manning coefficient $n=0.017 \mathrm{~s} / \mathrm{m}^{1 / 3}$. The pier is cylindrical with diameter $D=2 \mathrm{~m}$.

The flood occurrence is described by a homogenous Poisson process, with a mean annual frequency of occurrence of flood events of peak discharge $\mathrm{Q}>q_{0}=10 \mathrm{~m}^{3} / \mathrm{s}$ equal to $\lambda=2 \mathrm{yrs}^{-1}$. The peak flood discharge $Q$ for a given event is assumed to follow an exponential distribution, described by Eqn. (11), with scale parameter $\beta=25 \mathrm{~m}^{3} / \mathrm{s}$ and $q_{0}=10 \mathrm{~m}^{3} / \mathrm{s}$.

For simplicity, a triangular shape is assumed for the flood hydrograph, with a duration described by the relation $t_{\text {hyd }}(q)=0.0263\left(q-q_{0}\right)$ days [42]. According to this relation, the flood duration increases linearly with its peak discharge and it assumes a value equal to 5 days for $q=200 \mathrm{~m}^{3} / \mathrm{s}$. Fig. 3a shows the probability mass function of the number $N$ of occurrences of flood events with $Q>q_{0}$ for different design life times $t$, whereas Fig. $3 \mathrm{~b}$ shows the empirical CDF of the flow discharge for a given flow event of magnitude $Q>q_{0}$, obtained via Monte Carlo simulation with a set of $N_{\text {samples }}=10000$ samples of $Q$. The flow discharge values are such that scour occurs always under clear-water conditions.

(a)

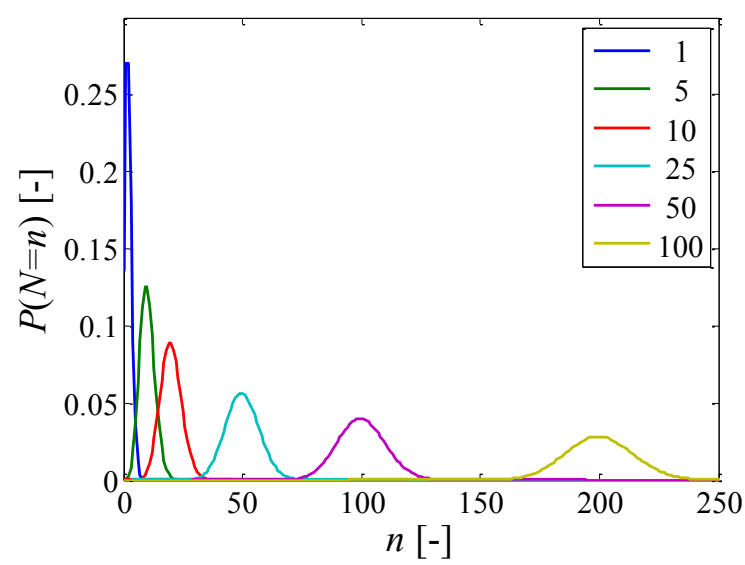

(b)

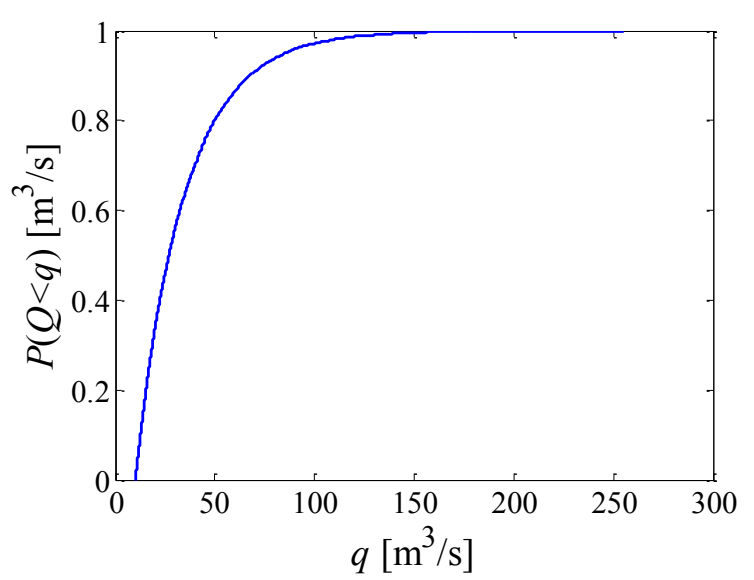

Fig. 3 a) Probability mass function of the number $N$ of occurrences of flood events with $Q>q_{0}$ for different times of observation $T$ (from 1 yrs to $100 \mathrm{yrs}$ ), b) Empirical cumulative distribution function of the flow discharge for a given flow event of magnitude $Q>q_{0}$.

The depth of flow $y_{0}$ is evaluated through the Manning formula for very wide channels (i.e. $B \square \quad$ ), providing the following rating curve relation:

$$
y_{0}=\left(\frac{n Q}{B S_{0}^{1 / 2}}\right)^{0.6}
$$

whereas the flow velocity is evaluated as: 


$$
V=\frac{Q}{B y_{0}}
$$

The temporal variation of the scour depth for a flood event with a given discharge is evaluated by employing the formula of Melville and Chiew [34] and following the procedure outlined in [10]. The formula of Melville and Chiew [34] is valid for the case of a flat hydrograph and clear-water conditions and reads as follows:

$$
s(t)=s_{e} \cdot \exp \left\{-0.03\left|\frac{V_{c}}{V} \ln \left(\frac{t}{t_{e}}\right)\right|^{1.6}\right\}
$$

where $s(t)$ is the scour depth at time $t, V$ is the flow velocity according to Eqn. (32), and $s_{e}$ and $V_{c}$ denote respectively the equilibrium scour depth and the critical velocity at threshold condition for sediment movement. The expression for these parameters can be found in [35].

In order to estimate the temporal evolution of the scour depth under non-steady hydrographs such as those considered in this study, reference can be made to [10]. The total flood duration time is subdivided into a set of smaller intervals, such that the flood is assumed steady in each interval with a flow discharge equal to the average value in that interval. For each interval, Eqn. (33) can then be used to evaluate the increase of scour depth by assuming as initial value of the scour depth the final value of the previous interval.

Fig. 4 illustrates the temporal evolution of the scour depth obtained by assuming a zero scour depth as initial condition, for a triangular hydrograph with peak magnitude $q=100 \mathrm{~m}^{3} / \mathrm{s}$, and for five repeated floods with the same magnitude. In the same figure, the temporal evolution of the scour depth under steady conditions and finite flood durations and the equilibrium depth for an infinite flood duration are also reported for comparison purposes.

It can be observed that considering the equilibrium value $\left(s_{e q}=2.5 \mathrm{~m}\right)$ results in a significant overestimation of the maximum depth that is attained during a single flood, and that even under 5 floods of the same intensity the equilibrium value is not attained. In fact, the maximum scour depth after one flood occurrence is equal to $1.76 \mathrm{~m}$, which is only $70 \%$ of $s$ eq, whereas the maximum scour depth after 5 flood occurrences is $2.18 \mathrm{~m}$, which is $87 \%$ of $s_{e q}$. In the case of floods with a lower peak discharge, the difference would even increase due to the lower duration of the flood. The flood hydrograph shape has also an influence on the maximum scour depth. In fact, considering a uniform hydrograph (steady conditions) during the finite flood duration rather than the triangular hydrograph (unsteady conditions) also yields an overestimation of the scour depth. 


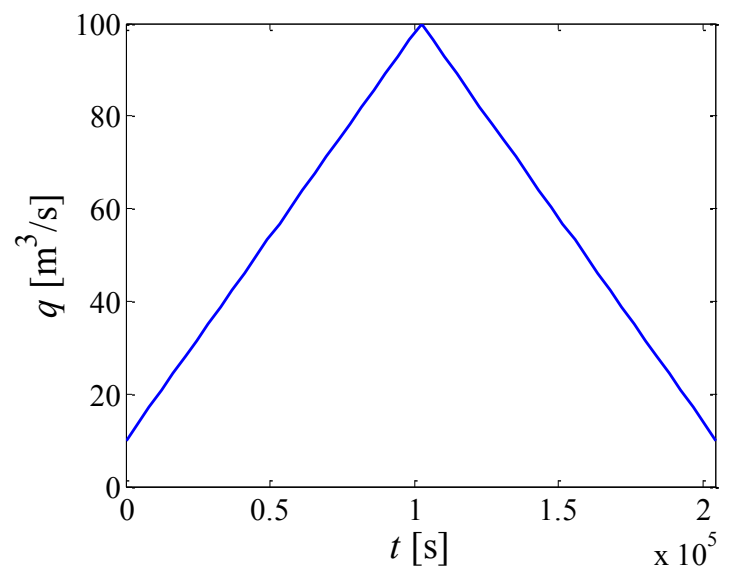

(c)

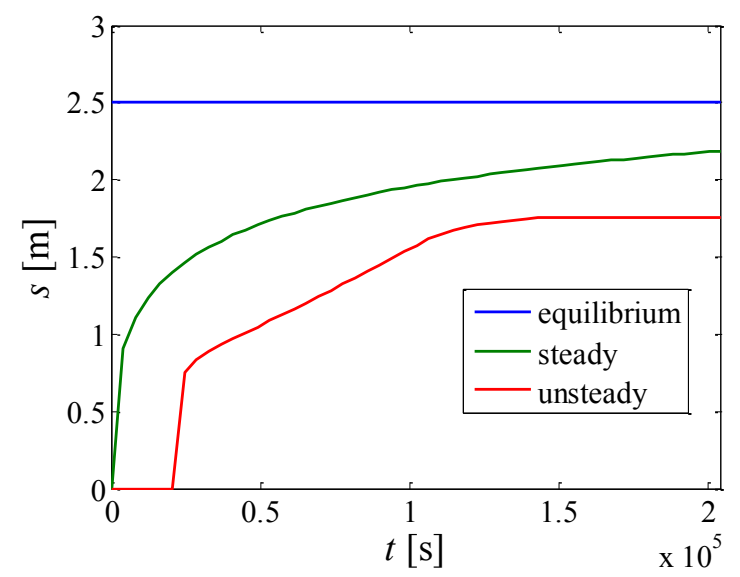

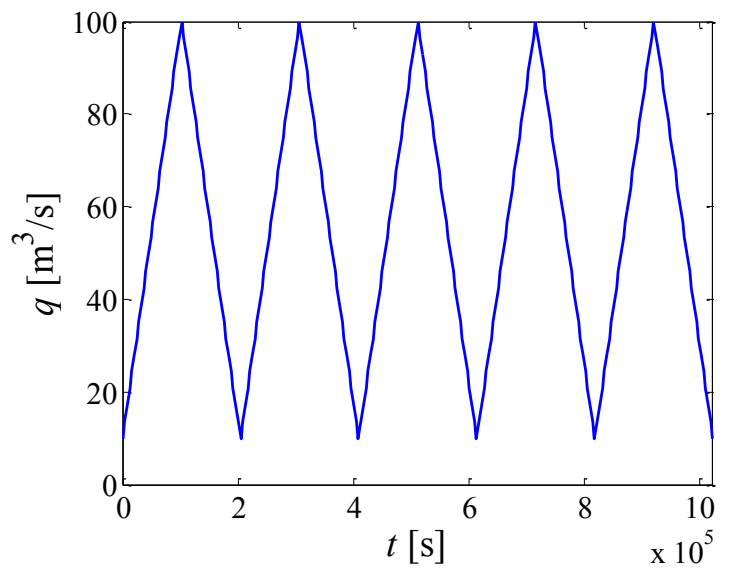

(d)

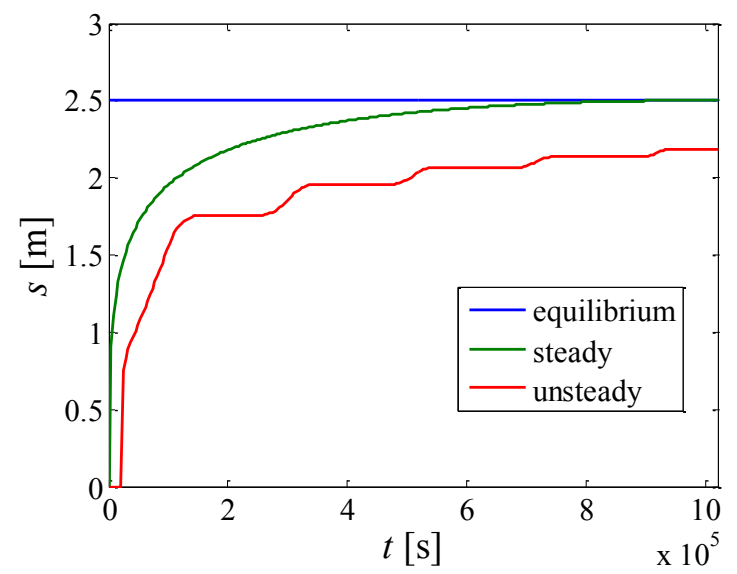

Fig. 4. Flood hydrographs (a,c) and relative temporal evolution of the scour depth for steady and unsteady flood conditions $(b, d)$.

Fig. 5 shows the empirical cumulative distribution functions of the maximum and equilibrium scour depth obtained for an initial scour depth equal to zero (Fig. 5a) and to $1.5 \mathrm{~m}$ (Fig. 5b), obtained by considering the set of 10000 samples of $Q$. It can be seen that if the actual shape of the hydrograph is taken into account, the maximum scour depth that can be attained is significantly lower than the equilibrium one. This confirms the fact that one flood is generally not sufficient to achieve the critical scour depth in clear-water conditions. Moreover, assuming a non-zero value of the scour depth affects significantly the distribution of the maximum scour depth, whereas the one of the equilibrium scour depth is not affected. 

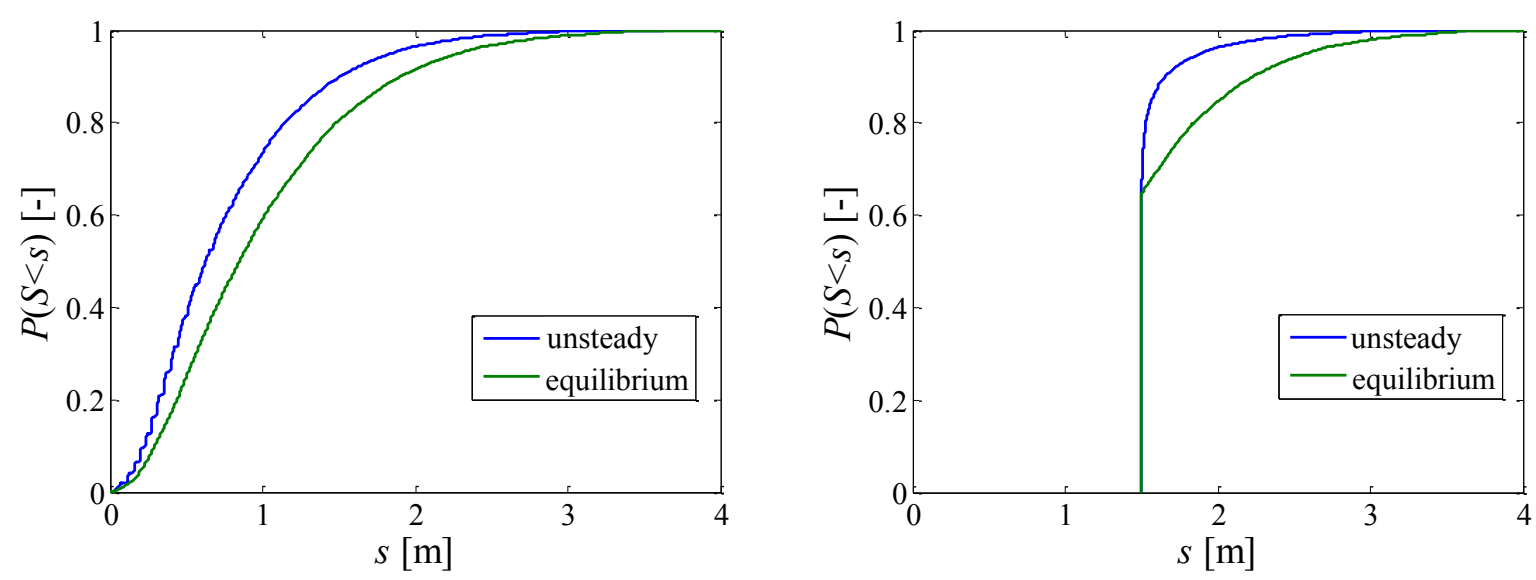

Fig. 5. Empirical cumulative distribution function of the maximum scour depth and of the equilibrium scour depth for a given flood event assuming (a) zero initial scour depth and (b) initial scour depth of $1.5 \mathrm{~m}$.

In order to compute the TPM $\boldsymbol{\Phi}$, a set of $N_{s}=25$ scour states is considered. For each of the $N_{\text {samples }}=10000$ samples of $Q$, the conditional TPM $\hat{\mathbf{\Phi}}(Q=q)$ needs to be computed first. This entails evaluating the maximum scour depth under unsteady conditions (i.e., by accounting for the actual flood hydrograph), for the $N_{s}$ different initial values of the scour depth. It is noteworthy that by assuming deterministic channel and pier properties $(B, D)$, and deterministic model parameters, there is a one-to-one relation between $Q$ and $S$. Thus, the transition from a scour depth to another for a given flood event, described by the conditional TPM $\hat{\mathbf{\Phi}}(Q=q)$, is also univocally defined by the $Q$ level.

The procedure for populating the TPM $\hat{\mathbf{\Phi}}(Q=q)$ is discussed for the case of a flood hydrograph with discharge $q=100 \mathrm{~m}^{3} / \mathrm{s}$. Based on the results reported in Fig. 4c, a scour depth $s=1.76 \mathrm{~m}$ is obtained if the initial value of the scour depth is $0 \mathrm{~m}$. This value of $s$ corresponds to a scour state 11 , and thus $\hat{\boldsymbol{\Phi}}_{1 j}(Q=100)=0$ for $j \neq 11$, and 1 for $j=11$. Assuming an initial scour depth of $1.5 \mathrm{~m}$ (state 10), a final value of the scour depth of $1.86 \mathrm{~m}$ (state 12) is obtained under a flood with $q=100 \mathrm{~m}^{3} / \mathrm{s}$. Thus, $\hat{\mathbf{\Phi}}_{10_{j}}(Q=100)=0$ for $j \neq 12$, and 1 for $j=12$. Finally, assuming an initial scour depth of $2 \mathrm{~m}$ (state 13), a flood with $q=$ $100 \mathrm{~m}^{3} / \mathrm{s}$ is too weak to induce any increase of the scour depth. Thus, $\hat{\mathbf{\Phi}}_{12 j}(Q=100)=0$ for $j \neq 12$, and 1 for $j=12$. This procedure can be automated and can be employed for estimating $\hat{\mathbf{\Phi}}\left(Q=q_{i}\right)$ for the $N_{\text {samples }}$ samples of $Q$. In general, under the assumption of clear-water conditions the scour hole can only increase (i.e., there is a zero probability of redeposited material) and therefore the scour state transition matrix for the sample flood discharge $q_{i}, \hat{\mathbf{\Phi}}\left(Q=q_{i}\right)$, has the form of an upper triangular matrix populated with zeros and ones.

After evaluating matrix $\hat{\boldsymbol{\Phi}}\left(Q=q_{i}\right)$ for each of the simulated $Q$ values, the matrix $\boldsymbol{\Phi}$ can be estimated based on Eqn. (23) as:

$$
\boldsymbol{\Phi}=E_{Q}[\hat{\boldsymbol{\Phi}}]=\frac{1}{N_{\text {samples }}} \sum_{i=1}^{N_{\text {samples }}} \hat{\boldsymbol{\Phi}}\left(Q=q_{i}\right)
$$

Fig. 6 shows a checkerboard-type plot of matrix $\hat{\boldsymbol{\Phi}}$ for $Q=32 \mathrm{~m}^{3} / \mathrm{s}$ and of matrix $\boldsymbol{\Phi}$, obtained by considering the 25 scour states. As expected, the final unconditional TPM is significantly different from the conditional one, since it is the result of the contribution of TPMs 
conditional on $Q$, weighted by the probability of occurrence of the $Q$. If a flood occurs when low scour depths have been previously developed, there is a high probability of increasing the scour depth, whereas if the scour hole is already very deep, there is a low probability of increasing it.

(a)

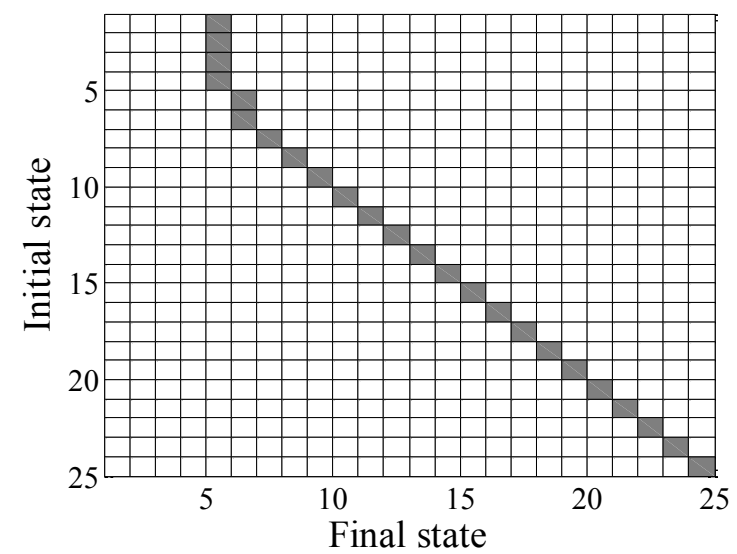

(b)

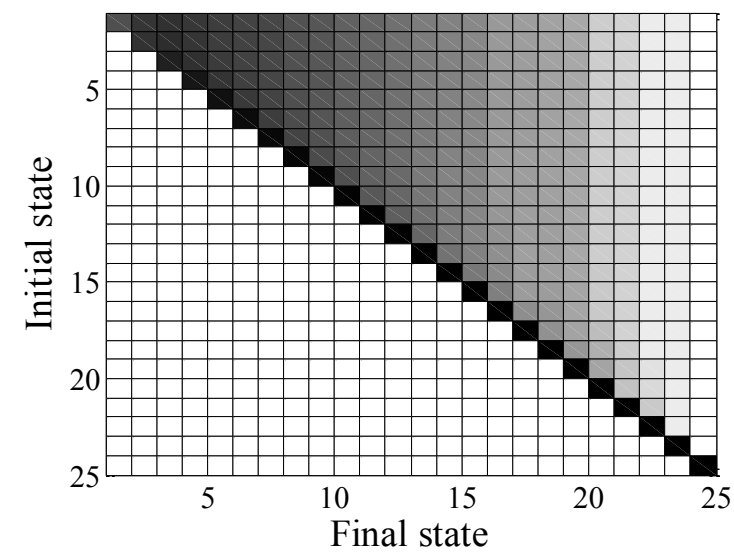

Fig. 6. Checkerboard-type plot of matrix $\hat{\boldsymbol{\Phi}}$ for $Q=32 \mathrm{~m}^{3} / \mathrm{s}$ (a) and of matrix $\boldsymbol{\Phi}(\mathrm{b})$.

The unconditional probability mass function $p_{j}(t)$ of the scour depth at different times $T$ can be obtained via Eqn. (27). Fig. 7 shows the values of $p_{j}$ obtained by assuming that the initial scour depth state is known deterministically and equal to 1 (i.e. $p_{j}^{0}=1$ for $j=1$ ).

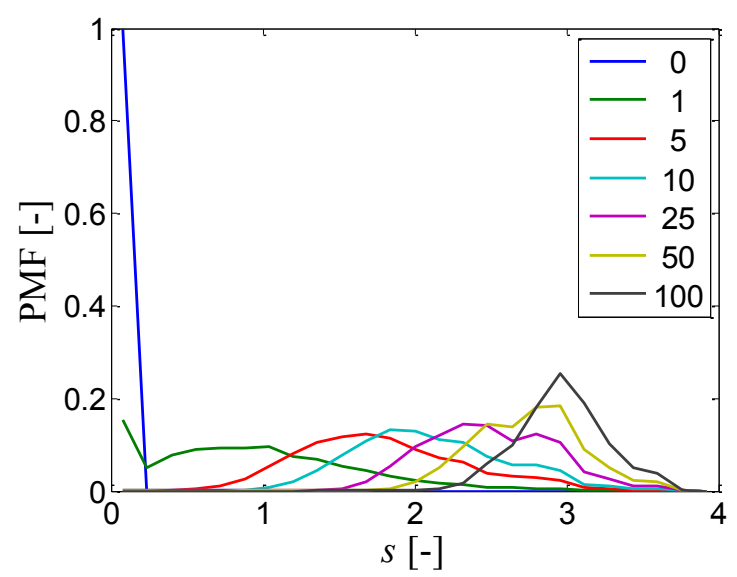

Fig. 7 Probability mass function of the scour depth at different times of observation $T$ (between $0 \mathrm{yr}$ and $100 \mathrm{yrs}$ after the initial one).

It can be observed that the PMF shifts towards higher values of the scour depth for increasing times of observation, and that it slowly tends to converge to a stationary value. Fig. 8 shows the variation with time of the expected value and of the standard deviation of the scour depth. As expected, the average scour depth increases with time, whereas the standard deviation decreases. This can be explained by observing in Fig. 7a that the PMF at time 1 yr presents two distant peaks, one at $0 \mathrm{~m}$ and one at $1 \mathrm{~m}$, whereas at time 100 yrs it has a very narrow shape and a single peak at $3 \mathrm{~m}$. 

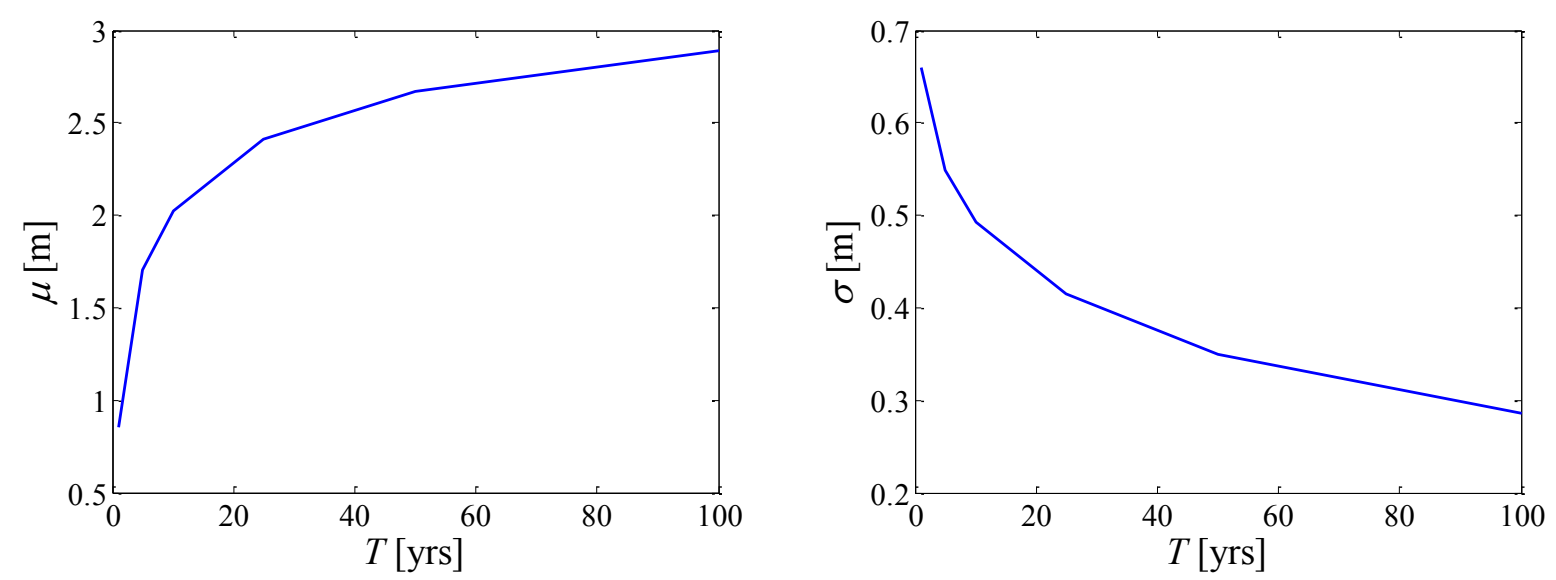

Fig. 8 Expected value (a) and standard deviation (b) of the scour depth vs. time of observation $T$.

Fig. 9a shows the CCDF for different design lifetimes. In Fig. 9b, the corresponding estimates obtained via Eqn. (A3) by assuming independence of the scour states at different times are reported. Obviously, accounting for history in estimating the scour depth distribution results in higher values of the scour depths. For example, a scour depth of $2.5 \mathrm{~m}$ has a probability of being exceeded in 20 years of $21 \%$ if the memory is taken into account, and of $15 \%$ if it is disregarded.

(a)

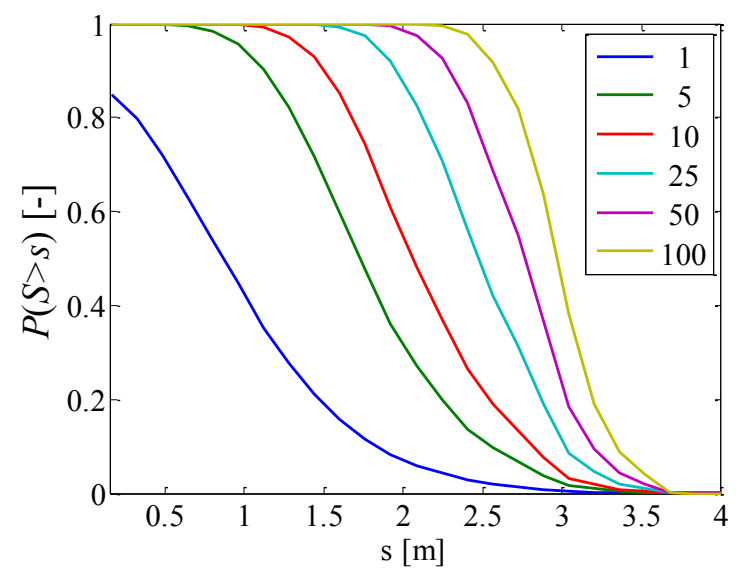

(b)

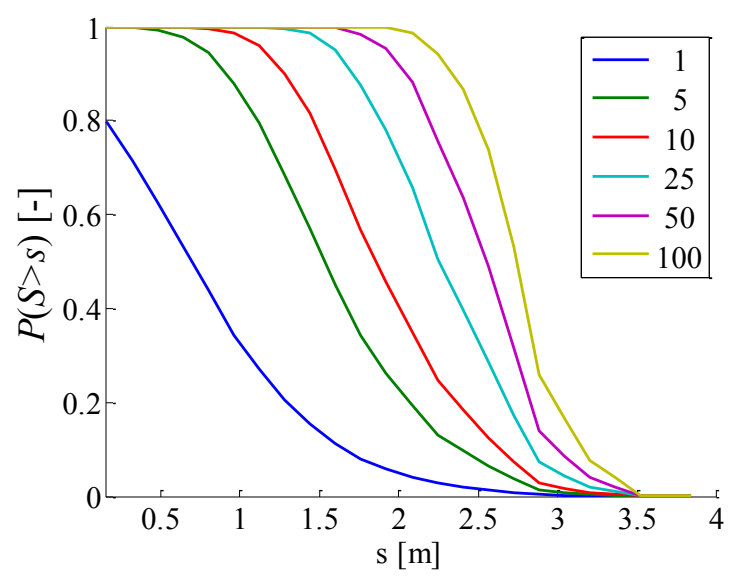

Fig. 9 CCDF of the scour depth at different times of observation $T$ (from 1 yrs to $100 \mathrm{yrs)} \mathrm{for} \mathrm{a} \mathrm{zero} \mathrm{initial} \mathrm{scour}$ depth obtained by considering memory (a) or by disregarding it (b).

\section{Effect of the initial scour state on scour development}

The effect of the initial scour state on the scour development is evaluated by assuming different initial state probabilities $\mathbf{p}(0)$ other than the one employed previously and corresponding to a zero initial depth. In particular, it is assumed that the initial scour state is known exactly and it is equal to $0.48 \mathrm{~m}, 0.96 \mathrm{~m}, 1.28 \mathrm{~m}, 1.92 \mathrm{~m}$, and $2.56 \mathrm{~m}$. It can be seen in Fig. 10 that the initial scour state influences significantly the scour depth for the first years of observation. In fact, after 25 years both the expected scour depth and standard deviation are about the same, irrespectively of the initial scour depth, for values of the initial depth smaller or equal to $1.92 \mathrm{~m}$. 

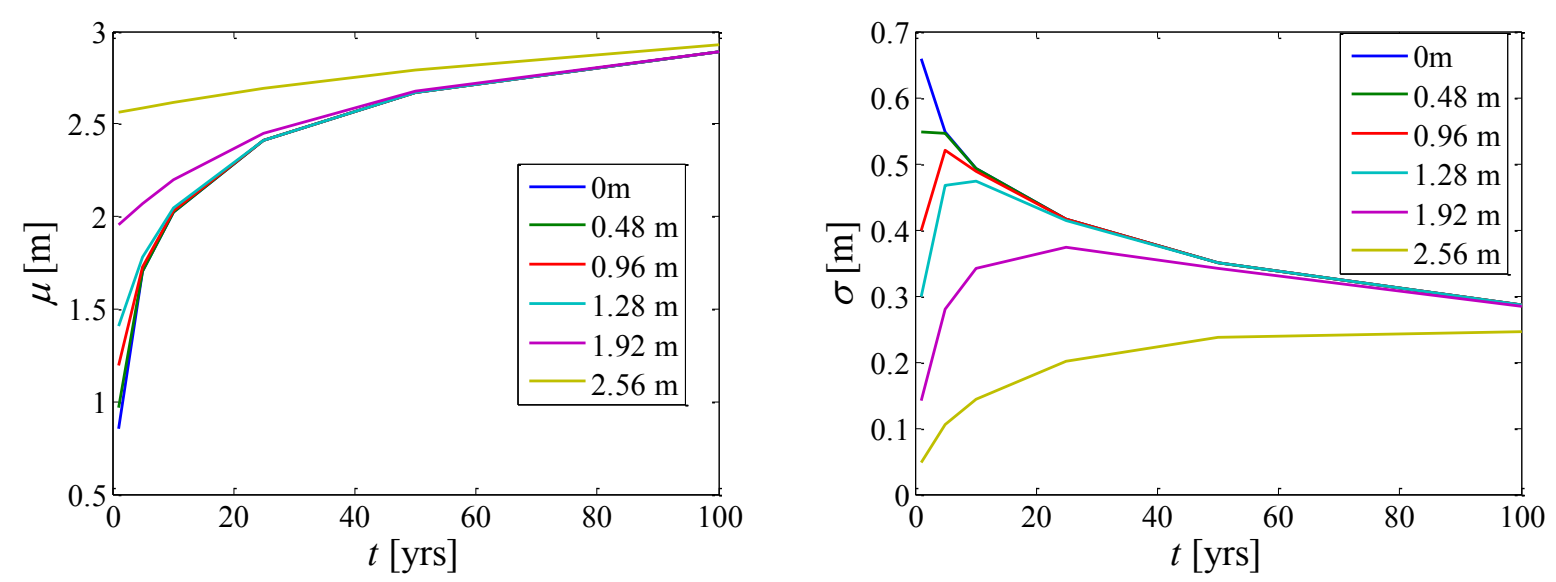

Fig. 10 (a) Expected value of the scour depth at different times, and (b) probability of scour depth exceedance for different values of the initial scour state $S_{0}$.

Fig. 11 shows the corresponding estimates of the probability of exceedance for a time of observation of $10 \mathrm{yrs}$ (Fig. 11a) and of $100 \mathrm{yrs}$ (Fig. 11b). As already pointed out, the initial scour depth has a significant influence only for the first years of observation, unless a very high initial scour depth is considered.

(a)

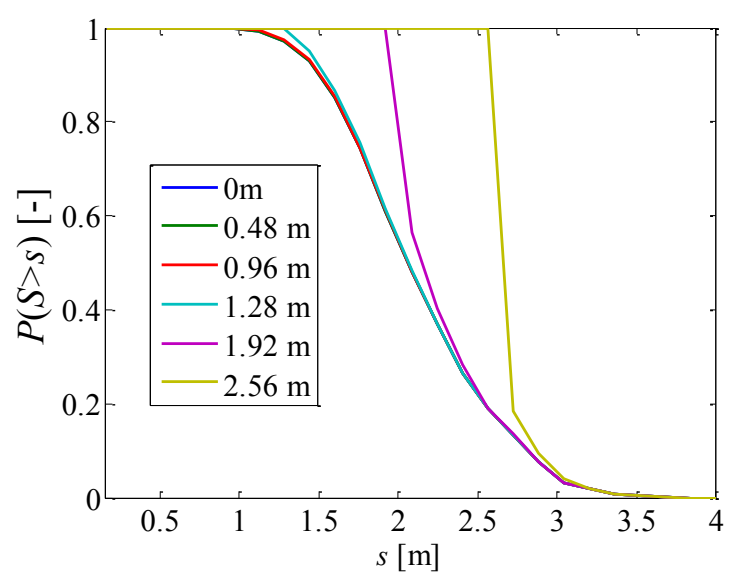

(b)

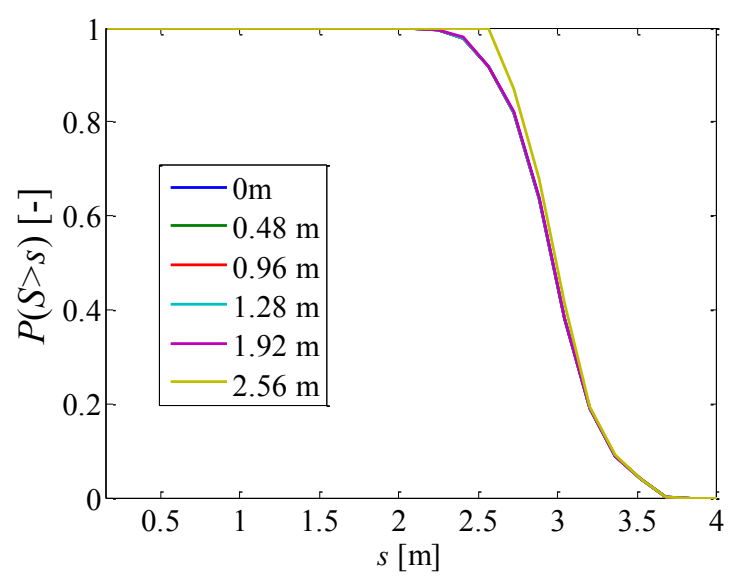

Fig. 11 Probability of exceedance of the scour depth after 10 yrs (a), and after 100 yrs (b) for different values of the initial scour state $S_{0}$.

\section{Effect of the uncertainty in the evaluation of the initial scour state}

In order to evaluate the effect of the uncertainty in the estimation of the initial scour state on the probability distribution of the scour depth at different times, a uniform distribution is assumed for the initial scour depth, with equal probabilities of being in any state. It is observed that the initial uncertainty on the scour state propagates at the different times of observation and results in a significant dispersion of the scour depth distribution. The expected values of the scour depth at the different times observed in this case are higher than the corresponding values observed for a zero initial scour depth (Fig. 8a). Also the standard deviation of the scour depth, which is not reported due to space constraints, is significantly higher. It assumes the value 1 at the first year, and it decreases with the same trend of Fig. $8 \mathrm{~b}$ until it reaches the value of 0.36 at 100 yrs. 
The uncertainty in the initial scour depth affects also the probability of scour depth exceedance, which is reported in Fig. 13. By comparing Fig. 13 with Fig. 9, it can be noted that the high uncertainty in the initial scour depth results in higher probability of exceedance of a given scour depth. These results are very useful in view of the difficulty in measuring with confidence the actual scour depth in bridge sites.

(a)

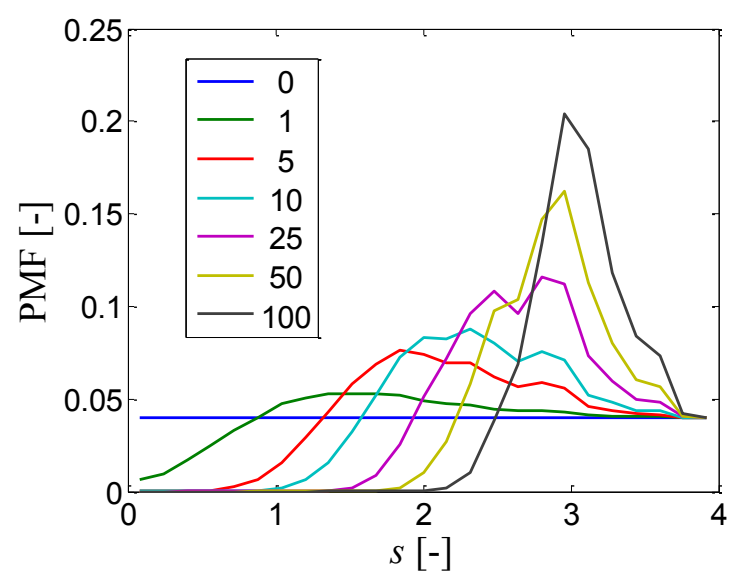

(b)

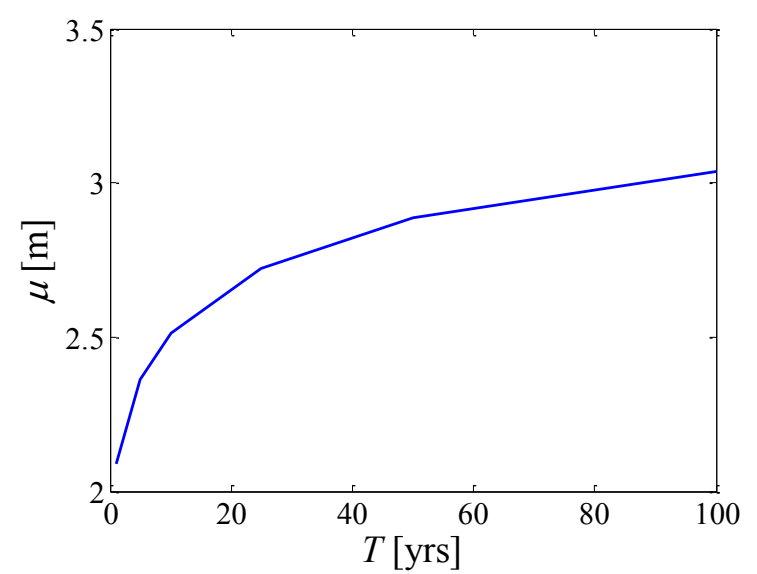

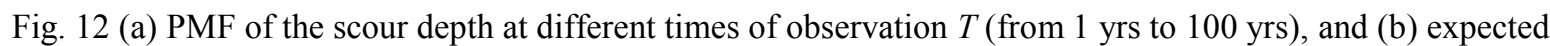
value of the scour depth vs. $T$ obtained by assuming an uniformly distributed initial scour depth.

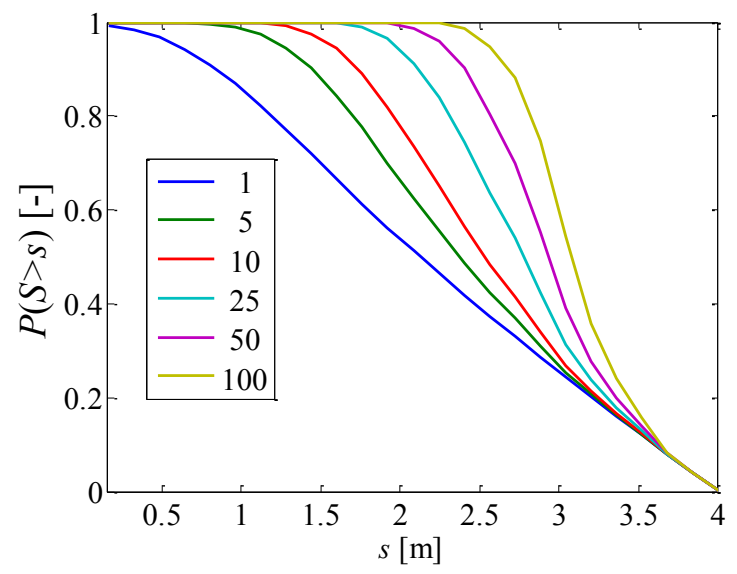

Fig. $13 \mathrm{CCDF}$ of the scour depth at different times of observation $T$ (from 1 yrs to $100 \mathrm{yrs)}$ obtained by assuming an uniformly distributed initial scour depth.

\section{Comparison with equilibrium scour depth estimates}

Fig. 14 shows the estimates of the CCDF of the scour depth obtained by assuming 1) the events of scour are independent identically distributed at the different flood occurrences and 2) the equilibrium scour depth rather than the maximum scour depth is attained. 


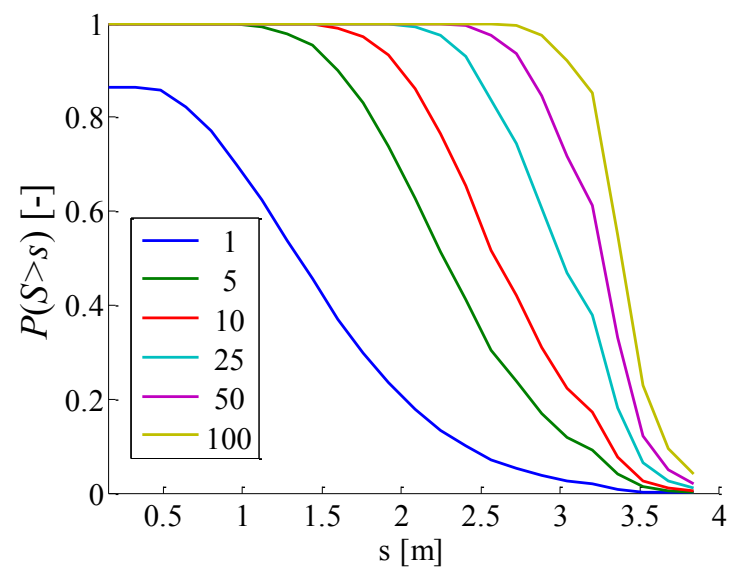

Fig. 14 CCDF of the scour depth at different times of observation $T$ (from 1 yrs to $100 \mathrm{yrs}$ ).

By comparing this figure with Fig. 9 it is observed that these assumptions, commonly employed in scour risk assessment procedures, lead to very high and unrealistic estimates of the scour depth. In fact, a scour depth of $2 \mathrm{~m}$ has a probability of being exceeded in 10 years equal to $90 \%$, which is much higher than the probability of exceedance evaluated by the proposed procedure accounting for memory (i.e., $50 \%$ ).

Another simplification introduced in current approaches is to consider only a single hazard level for the scour depth evaluation, which corresponds to a flood with a discharge characterized by a return period of 200 yrs. This return period corresponds to a value of $q=$ $161 \mathrm{~m}^{3} / \mathrm{s}$, and to an equilibrium scour depth $s_{e q}=3.56 \mathrm{~m}$. The proposed probabilistic scour assessment approach can also be used to compute the probability of exceedance corresponding to this value. For a time of observation of $100 \mathrm{yrs}$, the corresponding probability of exceedance is $3 \%$.

\section{CONCLUSION}

In this study, a probabilistic framework for local clear-water scour assessment is presented which allows estimating the temporal evolution of the probabilistic distribution of the scour depth by combining the information from hydrologic analysis, hydraulic analysis, and scour analysis. The proposed approach accounts for the random occurrence of subsequent flood events and for the uncertainty in the flood discharges as well as for the shape of the flood hydrograph. A Markov-model approach is employed to describe the changes in the scour depth for a given flood occurrence.

The proposed framework is applied to a simplified numerical example involving scour under clear-water conditions. The analysed example is highly idealised and by no means attempts to replicate a real case study. It is rather shown to illustrate and hopefully clarify the application of the proposed framework as well as to evaluate the effect of simplifying assumptions commonly employed in design practice. In particular, the following conclusions can be drawn from the results of the application:

- Although the scour development is controlled mainly by the peak flood discharge, also the hydrograph duration and shape have an important effect that should be taken into account.

- The history dependence of scour is an important factor that should be considered in evaluating the probabilistic distribution of the scour depth due to future flood events.

- The initial uncertainty on the scour depth measurement influences significantly the probability distribution of scour, especially in the first years of observation. However, 
regardless of initial conditions, the probability distribution of the scour depth evolves during time and tends to a stationary value that would be observed at time equal to infinity.

- Current approaches for scour risk assessment, which assume that scour events are independent and that the equilibrium scour depth is always attained, may lead to unrealistic and highly over-conservative estimates of the scour depth.

Further studies are required in order to develop tools for estimating the transition probability for a given flood by also accounting for the possibility of refilling of the scour hole under live-bed conditions, and for incorporating other sources of uncertainty such as those affecting the model and hydraulic parameters. A more realistic description of the flood hydrograph is also needed to achieve more reliable estimates of the scour depth evolution during the flood event.

\section{Acknowledgements}

The first author gratefully acknowledges support from the Marie Skłodowska-Curie Individual fellowship under Grant Agreement 657007 (Project Title: Flood Risk Assessment and mitigation for Masonry Arch Bridges, "FRAMAB", http://cordis.europa.eu/project/rcn/195375 en.html).

\section{REFERENCES}

[1] Lagasse PF, Ghosn M, Johnson PA, Zevenbergen LW, Clopper PE. Risk-Based Approach for Bridge Scour Prediction, Final report, NCHRP Project 24-34, Transportation Research Board of the National Academies, Washington, D.C; 2013.

[2] Melville BW, Coleman SE. Bridge scour, Water Resources Publications, Highlands ranch, Colorado, USA, 550pp, 2000.

[3] Richardson EV, Richardson JR. Bridge scour. In Woo DC, Fan SS. Proceedings of the Bridge Scour Symposium, Washington DC, U.S. Federal Highway Administration, RD-90-035, p. 1-42, 1989.

[4] Lu JY, Hong JH, Su CC, Wang CY, Lai JS. Field measurements and simulation of bridge scour depth variations during floods. Journal of Hydraulic Engineering 2008; 134(6): 810-821,.

[5] Jaudzems G. Multiple Flood Impact on the Local Scour at Water Engineering Structures on a Floodplain. PhD Thesis, Riga Technical University, Faculty of Building and Civil Engineering, Institute of Heat, Gas and Water technology, 121 pp, 2015.

[6] Kirby AM, Roca M, Kitchen A, Escarameia M, Chesterton OJ. Manual on scour at bridges and other hydraulic structures, second edition, CIRIA C742 Report, 2015.

[7] Yanmaz AM. Dynamic reliability in bridge pier scouring. Turkish Journal of Engineering and Environmental Sciences 2002; 26(4): 367-376.

[8] Kallias AN, Imam B. Probabilistic assessment of local scour in bridge piers under changing environmental conditions. Structure and Infrastructure Engineering 2016; 12(9): 1228-1241.

[9] Oliveto G, Hager WH. Temporal evolution of clear-water pier and abutment scour. Journal of Hydraulic Engineering 2016; 128(9): 811-820. 
[10] Chang WY, Lai JS, Yen CL. Evolution of scour depth at circular bridge piers. Journal of Hydraulic Engineering 2004; 130(9): 905-913.

[11] Oliveto G, Hager WH. Further results to time-dependent local scour at bridge elements. Journal of Hydraulic Engineering 2005; 131(2): 97-105.

[12] Van Noortwijk J, Kok M, Cooke R. Optimal maintenance decisions for the sea-bed protection of the Eastern-Scheldt barrier. In Engineering probabilistic design and maintenance for flood protection (pp. 25-56). Springer US.

[13] Johnson P, Ayyub B. Assessing Time-Variant Bridge Reliability due to Pier Scour. Journal of Hydraulic Engineering 1992; 118(6): 887-903.

[14] Brandimarte L, Montanari A, Briaud JL, D'Odorico P. Stochastic flow analysis for predicting river scour of cohesive soils. Journal of Hydraulic Engineering 2006; 132(5): 493-500.

[15] Briaud JL, Brandimarte L, Wang J, D'odorico P. Probability of scour depth exceedance owing to hydrologic uncertainty. Georisk 2007; 1(2): 77-88.

[16] Briaud JL, Ting FC, Chen HC, Gudavalli R, Perugu S, Wei G. SRICOS: Prediction of scour rate in cohesive soils at bridge piers. Journal of Geotechnical and Geoenvironmental Engineering 1999; 125(4): 237-246.

[17] Todorovic P. An Introduction to Stochastic Processes and Their Applications. New York: Springer-Verlag, 1992.

[18] Benedict ST, Caldwell AW. Development and evaluation of clear-water pier and contraction scour envelope curves in the Coastal Plain and Piedmont Provinces of South Carolina (No. 2005-5289). US Geological Survey, 2016.

[19] Van Leuwen Z, Lamb R. Flood and scour related failure incidents at railway assets between 1846 and 2013, JBA Trust Report No. W13-4224, 2014.

[20] Link O, Castillo C, Pizarro A, Rojas A, Ettmer B, Escauriaza C, Manfreda S. A model of bridge pier scour during flood waves, Journal of Hydraulic Research, 55:3, 310-323, 2017.

[21] Tung YK, Mays LW. Risk Analysis for Hydraulic Design. Journal of Hydraulic Division 1980; 106(HY5): 893-913.

[22] JCSS 2001. Probabilistic Model Code - Part 1: Basis of design. Joint Committee on Structural Safety.

[23] Todorovic P, Zelenhasic E. A Stochastic Model for Flood Analysis, Water Resources Research 1970; 6(6): 1641-1648.

[24] Lang M, Ouarda TBMJ, Bobee B. Towards operational guidelines for over-threshold modeling, J. Hydrol., 225, 103- 117, 1999.

[25] Madsen H, Rasmussen PF, Rosbjerg D. Comparison of annual maximum series and partial duration series methods for modeling extreme hydrologic events: 1. At-site modeling, Water Resources Research 1997; 33(4): 747- 757.

[26] Claps P. Laio F. Can continuous streamflow data support flood frequency analysis? An alternative to the partial duration series approach. Water Resources Research 2003; 39(8): 1216.

[27] Shane RM, Lynn WR. Mathematical model for flood risk evaluation. Journal of the Hydraulics Division 1964; 90(6): 1-20. 
[28] Hydrologic Engineering Center. (HEC-RAS). River Analysis System. User's Manual. Version 4.0. 2008.

[29] Johnson PA. Uncertainty of hydraulic parameters. Journal of hydraulic engineering 1996; 122(2), 112-114.

[30] Ettema, R., Constantinescu, G. \& Melville, B. Evaluation of bridge scour research: pier scour processes and predictions. NCHRP Report 175, 2011.

[31] Manes C, Brocchini M. Local scour around structures and the phenomenology of turbulence. Journal of Fluid Mechanics 2015; 779: 309-324.

[32] Gjunsburgs B, Jaudzems G, Govša J. Hydrograph Shape Impact on the Scour Development with Time at Engineering Structures in River Flow. Construction Science 2010; 11: 6-12.

[33] Sheppard DM, Demir H, Melville B. Scour at wide piers and long skewed piers, NCHRP Report 682, Transportation Research Board of the National Academies, 2011.

[34] Melville BW, Chiew YM. Time scale for local scour at bridge piers. Journal of Hydraulic Engineering 1999; 125(1): 59-65.

[35] Melville BW. Pier and abutment scour: integrated approach. Journal of hydraulic Engineering 1997; 123(2): 125-136.

[36] Kothyari UC, Hager WH, Oliveto G. Generalized approach for clear-water scour at bridge foundation elements. Journal of Hydraulic Engineering 2007; 133(11): 12291240 .

[37] Lança R, Fael C, Maia R, Pêgo J, Cardoso A. Clear-Water Scour at Comparatively Large Cylindrical Piers. Journal of Hydraulic Engineering 2013; 139(11): 1117-1125.

[38] Briaud JL, Gardoni P, Yao C. Statistical, risk, and reliability analyses of bridge scour. Journal of Geotechnical and Geoenvironmental Engineering 2013; 140(2): 04013011.

[39] Ghosn M, Moses F, Wang J. Design of Highway Bridges for Extreme Events. NCHRP Report 489, Washington DC, USA, 2003.

[40] Porter KA. An overview of PEER's performance-based earthquake engineering methodology. Proceedings of Ninth International Conference on Applications of Statistics and Probability in Civil Engineering, 2003.

[41] Barbato M, Petrini F, Unnikrishnan VU, Ciampoli M. Performance-based hurricane engineering (PBHE) framework. Structural Safety 2013; 45: 24-35.

[42] Cunderlik JM., Ouarda TB. Regional flood-duration-frequency modeling in the changing environment. Journal of Hydrology 2006; 318(1): 276-291.

\section{APPENDIX}

\section{Memory-less scour events}

Assuming that the scour depths at the different flood events are independent and identically distributed with probability mass function $P\left[S(t)=s_{j}\right]$ is equivalent to assuming that:

$$
P\left[\max _{k=1,2, \ldots, \mathrm{n}} S_{n}(t) \leq s_{j}\right]=P S_{1}(t) \leq s_{j} \cap S_{2}(t) \leq s_{j} . \cap \cap S_{n}(t) \leq s_{j}=\left(P\left[S(t) \leq s_{j}\right]\right)^{n}=\left(\sum_{i=1}^{j} P\left[S=s_{i}\right]\right)^{n}
$$


Thus, the relevant risk of exceeding the scour state $j$ in $T$ years is:

$$
\begin{aligned}
& P\left[S \geq s_{j}\right]=1-\sum_{n=0}^{\infty}\left(P\left[S \geq s_{j}\right]\right)^{n} \cdot p_{n}(T)=1-e^{-\lambda T} \sum_{n=0}^{\infty}\left(P\left[S \leq s_{j}\right]\right)^{n} \frac{(\lambda T)^{n}}{n !}= \\
& =1-e^{-\lambda T} \sum_{n=0}^{\infty} \frac{\left(\lambda T \cdot \sum_{k=1}^{j} P\left[S=S_{k}\right]\right)^{n}}{n !}=1-e^{-\lambda T} e^{\lambda T\left[\sum_{i=1}^{j} P\left[S=s_{i}\right]\right]}=1-e^{-\lambda\left(1-\sum_{i=1}^{j} P\left[S=s_{i}\right]\right) T}
\end{aligned}
$$

The term $1-\sum_{i=1}^{j} P\left(S=s_{k}\right)$ in Eqn. (A2) denotes the probability of exceeding the scour depth $s_{j}$ for a given flood event. In the case of continuous scour states, the scour depth can be described as a continuous random variable with probability density function $p_{S}(s)$ and $\mathrm{CCDF} G_{S}(s)$, and Eqn.(A2) becomes:

$$
P[S>S]=1-e^{-\lambda T G_{S}(s)}
$$

where $\lambda_{S}(s)=\lambda G_{S}(s)$ denotes the mean annual frequency of the scour depth exceeding the depth $s$, given by:

$$
\begin{aligned}
& \lambda_{S}(s)=\lambda G_{S}(s)=\iint_{q} G_{S \mid H}(s \mid h) p_{H \mid Q}(h \mid q) \cdot d h \cdot\left|d \lambda_{Q}(q)\right|= \\
& =\lambda \iint_{q} G_{S \mid H}(s \mid h) p_{H \mid Q}(h \mid q) \cdot p_{Q}(q) \cdot d h \cdot d q
\end{aligned}
$$

This equation is very similar to the one used in the Performance-based Earthquake Engineering framework [40] or the Performance-based Hurricane Engineering framework [41], and it corresponds to modelling the occurrence of events of scour depth exceeding $s$ as a filtered Poisson process with MAF $\lambda_{s}(s)$. It is also noteworthy that in the absence of memory effects one should be able to obtain the same results by considering the annual maxima (as in [8]) rather than the peak over threshold floods. 